\title{
Iron in seeds - loading pathways and subcellular localization
}

\section{Louis Grillet ${ }^{1}$, Stéphane Mari ${ }^{2}$ and Wolfgang Schmidt ${ }^{1}$ *}

1 Institute of Plant and Microbial Biology, Academia Sinica, Taipei, Taiwan

2 Plant Biology, Institut National pour la Recherche Agronomique, Montpellier, France

\section{Edited by:}

Raul Antonio Sperotto, Centro Universitário Univates, Brazil

\section{Reviewed by:}

Takanori Kobayashi, Ishikawa Prefectural University, Japan Janette Palma Fett, Universidade Federal do Rio Grande do Sul, Brazil Kyoko Higuchi, Tokyo University of Agriculture, Japan

\section{${ }^{*}$ Correspondence:}

Wolfgang Schmidt, Institute of Plant and Microbial Biology, Academia Sinica, Academia Road 128, Taipei 11529, Taiwan

e-mail:wosh@gate.sinica.edu.tw

Iron $(\mathrm{Fe})$ is one of the most abundant elements on earth, but its limited bioavailability poses a major constraint for agriculture and constitutes a serious problem in human health. Due to an improved understanding of the mechanisms that control Fe homeostasis in plants, major advances toward engineering biofortified crops have been made during the past decade. Examples of successful biofortification strategies are, however, still scarce and the process of Fe loading into seeds is far from being well understood in most crop species. In particular in grains where the embryo represents the main storage compartment such as legumes, increasing the seed Fe content remains a challenging task. This review aims at placing the recently identified actors in Fe transport into the unsolved puzzle of grain filling, taking the differences of $\mathrm{Fe}$ distribution between various species into consideration. We summarize the current knowledge on Fe transport between symplasmic and apoplasmic compartments, and provide models for Fe trafficking and localization in different seed types that may help to develop high seed Fe germplasms.

\section{Keywords: biofortification, grain filling, Fe transport, Fe storage, Fe in seeds}

\section{INTRODUCTION}

Iron $(\mathrm{Fe})$ is involved in the transport of electrons in many ubiquitous metabolic processes such as respiration and photosynthesis, and is required as a co-factor of numerous enzymes. Although highly abundant in the earth's crust, the low solubility of Fe often limits plant growth. This is largely due to the high reactivity of Fe toward oxygen: in soils, Fe tends to form highly insoluble ferric hydroxides, dramatically restricting the bioavailability of Fe. Undernourishment for Fe decreases productivity and yield, posing a major constraint for both agriculture and human health. Among the essential micronutrients, Fe is considered as the most deleterious when present in insufficient amounts (Stoltzfus, 2003; Zimmermann and Hurrell, 2007). In plant-based diets, Fe is provided as non-heme Fe that is less well absorbed than heme-bound Fe in meat, causing Fe deficiencyinduced anemia (FDA) in areas where monotonous, plant-based diets are dominating (USA National Institute of Health, Office of Dietary Supplements, http://ods.od.nih.gov/factsheets/IronHealthProfessional/). Combating FDA requires strategies to increase the Fe content in crops and, as a prerequisite for the development of such strategies, a better understanding of the mechanisms that control transport of $\mathrm{Fe}$ to and storage of Fe in edible plant tissues, as well as the chemical forms in which $\mathrm{Fe}$ is present in these tissues.

Efforts toward understanding Fe uptake have been mainly focused on roots (Eide etal., 1996; Robinson et al., 1999; Curie et al., 2001; Nozoye et al., 2011). Plants are traditionally separated into two strategies by which they acquire Fe from the soil (Römheld and Marschner, 1983). Strategy I plants, which include all plants except grasses, acquire $\mathrm{Fe}$ after reduction of $\mathrm{Fe}^{\mathrm{III}}$ chelates by a plasma membrane (PM)-bound ferric chelate reductase (FRO2 in Arabidopsis; Robinson et al., 1999); the resulting $\mathrm{Fe}^{\mathrm{II}}$ is then taken up by a transporter of the ZIP family (Iron-Regulated Transporter1, IRT1, in Arabidopsis; Eide et al., 1996; Vert et al., 2002). The solubility of Fe is increased by the P-type ATPase-mediated proton excretion (AHA2 in Arabidopsis; Santi and Schmidt, 2009), which decreases the rhizosphere $\mathrm{pH}$ and increases $\mathrm{pFe}$ in the soil solution. Graminaceous plants take up $\mathrm{Fe}$ by secreting plantborne chelators (phytosiderophores) of the mugineic acid family with high affinity to $\mathrm{Fe}^{\mathrm{III}}$ via TOM1 (Nozoye et al., 2011), and the $\mathrm{Fe}^{\mathrm{III}}$-phytosiderophore complex is taken up by a YELLOW STRIPE/YELLOW STRIPE1-like (YSL) family transporter without prior reduction (Curie et al., 2001). Recent findings have faded the border between the two strategies. Iron binding compounds of the coumarin and flavin families have been identified in root exudates of Arabidopsis and Medicago truncatula (Fourcroy et al., 2013; Rodriguez-Celma et al., 2013). Similar to phytosiderophores, these compounds mobilize non-bioavailable Fe. Secretion of phenolic compounds was also observed in the strategy II plant rice (Bashir et al., 2011; Ishimaru et al., 2011). Another deviation from the initial strategy I/strategy II concept is the presence of a functional $\mathrm{Fe}^{2+}$ transporter (OsIRT1) in rice roots (Ishimaru et al., 2006).

The flow of Fe through the plant involves the Fe chelators nicotianamine (NA), citrate, and deoxymugineic acid (DMA), which act as chaperones to avoid precipitation and cellular damage by the formation of harmful reactive oxygen species through Fenton chemistry, as well as proteins capable of transporting either these molecules as such or their Fe chelates (Le Jean et al., 2005; Waters et al., 2006; Durrett et al., 2007; Inoue et al., 2009; Rogers et al., 2009; Yokosho et al., 2009; Nishiyama et al., 2011). Ultimately, Fe has to be transported to the places of highest demand, the photosynthetic electron transport chains in leaves, 
the reproductive organs (Roschzttardtz et al., 2013), and to the seeds where Fe is stored to support embryogenesis. Despite the importance for human nutrition, the latter process is poorly understood. In this review, we are aiming at providing an update on the mechanisms that transports Fe from roots to the seed and to emphasize the current knowledge gaps in the framework of Fe transport to the seeds. We will focus on the proteins involved in this process as well as on the chemical forms of Fe they transport. Finally, we will also discuss the differences in Fe localization between seeds of various plant species and their consequences in terms of chemical speciation and nutritional properties.

\section{IRON TRANSPORT IN THE SHOOT AND UPTAKE OF Fe INTO AERIAL PLANT PARTS}

In contrast to the abundant data on root Fe uptake and its regulation (for reviews see Palmer and Guerinot, 2009; Hindt and Guerinot, 2012; Thomine and Vert, 2013), relatively little is known regarding $\mathrm{Fe}$ transport in shoots. Before reaching the chloroplasts and mitochondria where it is highly required, Fe has to be unloaded from the xylem, distributed to the different tissues, and transported across the PM of the sink cells. None of these mechanisms has yet been deciphered, possibly due to difficulties derived from functional redundancy of transporters involved and possible feedback loops to recalibrate Fe homeostasis in these tissues. In dicots, Fe circulates in the xylem as ferric-citrate complexes (Durrett et al., 2007; Rellan-Alvarez et al., 2010). It has been suggested that Fe uptake by shoot cells is achieved through an IRT-like transporter after reduction of $\mathrm{Fe}$ in $\mathrm{Fe}^{\mathrm{III}}$ chelates to $\mathrm{Fe}^{\mathrm{II}}$ (Jeong and Connolly, 2009; Palmer and Guerinot, 2009). A candidate for the uptake of Fe into leaf cells is the PM-localized transporter AtIRT3. The protein is highly produced in the xylem and in mesophyll cells (Lin et al., 2009), and was shown to mediate Fe uptake in Arabidopsis (Shanmugam et al., 2011). The Fe ${ }^{\mathrm{III}}$ reduction system that is likely to co-operate with an IRT-type transporter is a ferric-chelate reductase of the FRO family (Figure 1). In Arabidopsis, the most highly expressed member of this gene family in shoots is AtFRO6 (Wu et al., 2005; Mukherjee et al., 2006), encoding a protein located on the PM (Jeong et al., 2008). However, fro6 knock-out lines do not display any phenotype (Jeong and Connolly, 2009), arguing against an essential function of FRO6 in leaf Fe uptake. Other members of the FRO family are either not expressed in shoots or localized to intracellular compartments, suggesting other, FROindependent reduction mechanisms. Although in aerial plant parts photoreduction of $\mathrm{Fe}^{\mathrm{III}}$ is likely to occur, the extent to which this process contributes to the overall reduction of Fe in leaves remains to be elucidated. Iron in ferric-citrate complexes is particularly sensitive to this process (Bienfait and Scheffers, 1992), resulting in a fast and complete reduction of $\mathrm{Fe}^{\mathrm{III}}$ accompanied by degradation of citrate and a rise in $\mathrm{pH}$. As $\mathrm{Fe}^{\mathrm{III}}$-citrate is the predominant form of Fe in the xylem, photoreduction may represent an important component of xylem unloading. Alternatively, $\mathrm{Fe}^{\mathrm{III}}$ could also be reduced by direct reaction with molecules such as ascorbate (Figure 1). Ascorbic acid is present in millimolar concentrations in most tissues and in all cellular compartments including cell walls of both dicots and grasses (Rautenkranz et al., 1994; Foyer and Lelandais, 1996; Conklin et al., 2000). Ascorbic acid is able to reduce $\mathrm{Fe}^{\mathrm{III}}$-chelates in vitro (Grinstead, 1960; Römheld and
Marschner, 1983), and its properties to facilitate Fe transport in mammalians are well described (Sayers et al., 1973; Hallberg et al., 1989; Lane and Lawen, 2008). Several studies show a strong negative correlation between Fe and ascorbic acid (AsA) concentration; therefore, $\mathrm{Fe}^{\mathrm{III}}$ reduction by ascorbic acid is likely crucial for $\mathrm{Fe}$ transport in shoots (Zaharieva and Abadía, 2003; Urzica et al., 2012).

\section{REMOBILIZATION AND DISTRIBUTION OF Fe}

Contrary to the uptake of Fe into leaf cells, its distribution within the plants is relatively well documented. A key role in this process is played by the Fe chelator NA. Despite high Fe concentrations in leaves, the NA-deficient tomato mutant chloronerva develops Fe-dependent interveinal chlorosis that can be corrected by exogenous application of NA (the "normalizing factor"; Procházka and Scholz, 1984). The phenotype of chloronerva plants is caused by defective expression of the gene encoding NA synthase, NAS (Ling et al., 1999). In Arabidopsis, a similar phenotype was observed in the nas $4 x$ quadruple mutant, which harbors mutations in all four Arabidopsis NAS genes (Klatte et al., 2009). In nas $4 x$ plants, the flower, and seed Fe content were also affected, indicating a function of NA in intercellular Fe distribution (Klatte et al., 2009; Schuler et al., 2012). NA is a non-proteinogenic amino acid, structurally analogous to and a precursor for phytosiderophores of the DMA family (Noma et al., 1971). Implication of NA in Fe distribution was further demonstrated by functional characterization of the Fe-NA transporter YELLOW STRIPE1 in maize (Schaaf et al., 2004) and other members of this gene family in several species including rice and Arabidopsis (Le Jean et al., 2005; Waters et al., 2006; Gendre et al., 2007; Inoue et al., 2009; Ishimaru et al., 2010). In Arabidopsis, AtYSL1, and AtYSL3 were shown to be involved in the shoot to seed translocation of Fe; loss-of-function mutants displayed a decrease of both Fe and NA in seeds (Le Jean et al., 2005; Waters et al., 2006). A similar function has been attributed to OsYSL2 in rice (Ishimaru et al., 2010). To date, there are only two reports on Fe speciation in the phloem sap. The first study was conducted on Ricinus communis, revealing the presence of an $\mathrm{Fe}$ transport protein (RcITP; Krüger et al., 2002). A later work conducted in rice showed that DMA is the major Fe chelator in the phloem of this species, whereas NA was in fact mainly bound to zinc (Nishiyama et al., 2011).

\section{PHLOEM LOADING AND UNLOADING OF Fe}

In the current view of phloem loading, Fe is bound to NA and transported into the sieve tubes by YSL proteins (Koike et al., 2004; reviewed in Curie et al., 2009). It is, however, unclear whether the Fe transported by YSLs is localized in the cytosol or in the apoplast. The exchange of solutes between the phloem and surrounding tissues occurs either through plasmodesmata, or across the PMs of adjacent companion or vascular parenchyma cells (Lalonde et al., 2003). The later path requires Fe to be present in the cell wall. Fe-NA is unstable at the slightly acidic pH of the cell wall and Fe-citrate is the predominant form of Fe in apoplasmic environment (von Wiren et al., 1999; Rellan-Alvarez et al., 2008). In such a context, formation of the Fe-NA complex would be rate limiting for phloem loading and unloading (Figure 1). A major caveat to this scenario is the absence of any characterized PM-bound 


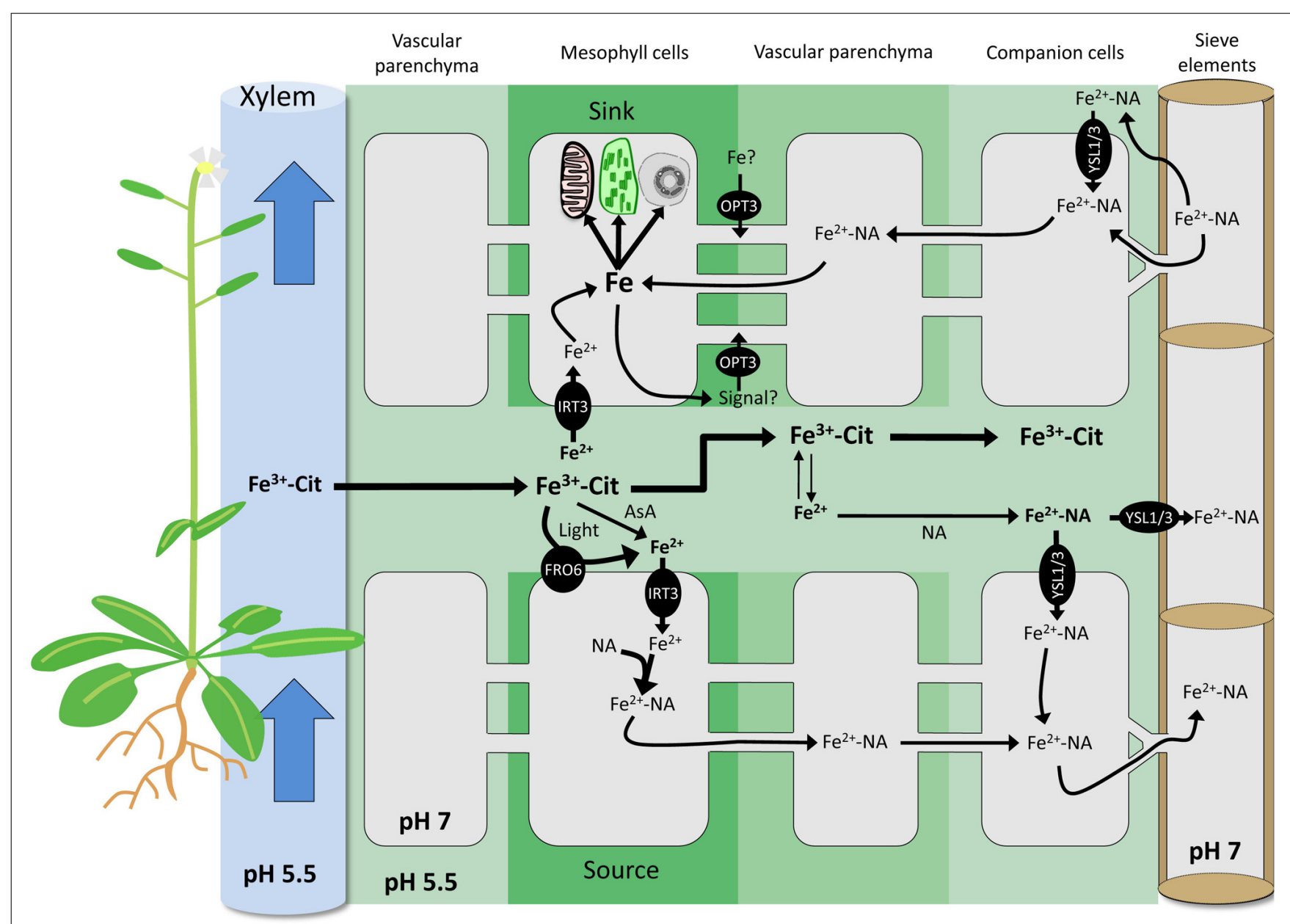

FIGURE 1 | Exchange of Fe between apoplasmic and symplasmic compartments in Arabidopsis. Root Fe is translocated to shoots through the xylem as Fe $\mathrm{F}^{\mathrm{III}}$-citrate complexes by bulk flow. Fe ${ }^{\mathrm{III}}$ can be reduced by light, extracellular AsA, and PM-bound ferric reductases of the FRO family. AtFRO6 and AtIRT3 are likely candidates to mediate Fe reduction and uptake in Arabidopsis shoots in both sink and source cells. In the cytoplasm, highly reactive $\mathrm{Fe}^{\mathrm{Il}}$ is complexed by NA. In the apoplasm, $\mathrm{Fe}^{\mathrm{Il}}$ is oxidized to Fe $\mathrm{Fe}^{\mathrm{III}}$ and chelated by citrate. The formation of Fe-NA complexes in the apoplasm may occur to some extent. Apoplasmic Fe-NA can be taken up by PM-localized YSL transporters. In the cytoplasm, the prevalent Fe form is Fe-NA, which can readily circulate through the symplasmic path. Fe-NA moves from cell-to-cell through plasmodesmata passively by bulk flow. In the phloem, Fe is presumably mainly present as Fe-NA. In sink organs, Fe-NA can exit the phloem via plasmodesmata, or diffuse out of sieve elements into the apoplasm. In the latter scenario, Fe is retrieved by YSLs or by AtOPT3. Iron derived both from the apoplasm and from the symplasmic pathway constitutes the intracellular Fe pool. Plants possess yet unknown sensing and signaling mechanisms to regulate the size of this pool. AtOPT3 has been also suggested to transport signaling molecules that could circulate from the shoot to the root through the phloem, thereby negatively regulating root Fe uptake. AsA, ascorbic acid; Cit, citrate; FRO, Ferric Reductase Oxidase; IRT, Iron-Regulated Transporter; NA,

nicotianamine; OPT, OligoPeptide Transporter; YSL, Yellow Stripe-Like; PM, plasma membrane.
Fe efflux transporters in plants. In Arabidopsis, a homolog of the mammalian Fe exporter ferroportin (FPN), FPN1, was suggested to perform such a function (Morrissey et al., 2009).

Plasmodesmata function is complex and the mechanisms that determine the selectivity of the transported solutes are not clearly defined. So far, no plasmodesma-localized YSL transporter has been identified. Interestingly, such a location was demonstrated for AtOPT3 (Fernandez-Calvino et al., 2011), a member of the oligopeptide transporters (OPT) protein family with Fe transport activity in yeast (Wintz et al., 2003). Disruption of this gene severely affects cellular Fe homeostasis (Stacey et al., 2008); opt3 knock-down lines (i.e., opt3-2) display constitutive overexpression of IRT1 and FRO2 in roots, despite of accumulation of high Fe levels in leaves. Members of the OPT family were shown to transport peptides (Lubkowitz et al., 1997; Lubkowitz et al., 1998) and AtOPT3 is thus an unlikely candidate for the transport of free Fe. Potential transport of a Fe-ligand conjugate has not been tested yet. It was hypothesized that AtOPT3 might transport signaling molecules involved in phloem loading and/or Fe sensing (Stacey et al., 2008; García et al., 2013). Iron accumulation in the distal ends of siliques, in the funiculus and in vascular tissues of the seed coat of opt3-2 plants suggests an impairment of the unloading of Fe from the phloem rather than compromised loading. Whether AtOPT3 functions in the transport of Fe or plays other roles in $\mathrm{Fe}$ homeostasis, for example by transporting a signal molecule or a ligand, remains to be elucidated (Figure 1). 
The existence of mutants with similar phenotypes in other species, such as the pea mutant degenerative leaves ( $d g l)$, which shows a constitutively activated Fe deficiency response in roots despite high Fe concentrations in leaves (Grusak and Pezeshgi, 1996), points to a conserved regulation mechanism of root $\mathrm{Fe}$ uptake through shoot-to-root communication. Phloem Fe is likely to be essential in this process (García et al., 2013). Thus, unraveling the loading and unloading processes would provide a comprehensive picture of plant Fe homeostasis which may reveal new targets for breeding biofortified crops.

\section{CONTRIBUTIONS OF THE XYLEM AND THE PHLOEM TO SEED LOADING OF Fe}

Iron loaded into seeds arrives either via xylem vessels or via the sieve tubes of the phloem. Both paths circulate around the seed coat. Nutrients are not directly unloaded into the endosperm (Van Dongen et al., 2003; Stadler et al., 2005), implying the need for an active and selective transport from the integument to the endosperm. The passage from the funiculus to the embryo requires at least two shifts between the symplasmic and apoplasmic path: unloading of Fe from the phloem into the endosperm and transport from the endosperm to the embryo (Patrick and Offler, 2001). Iron delivered via the xylem derives from the uptake of Fe from the rhizosphere; hence, its concentration depends directly on the expression of IRT1 and FRO2 (Brown and Chaney, 1971; Blair et al., 2010). This pool of Fe is readily transported as Fe $\mathrm{FII}^{\mathrm{III}}$ chelate to the aerial parts (Durrett et al., 2007), where it is taken up by leaf cells and ultimately reaches the seed coat. Thus, xylem Fe contributes directly to both shoot Fe and seed Fe levels. Phloem Fe derives from remobilization of Fe in senescing leaves, likely present as Fe-NA complex. Therefore, the size of the phloem Fe pool is determined on one hand by remobilization mechanisms, i.e., by NA synthesis and by Fe-NA transport via YSL proteins, and on the other hand by the shoot Fe concentration, that was established by the root uptake system during the plant's life. With this in mind, it is not surprising that xylem Fe was considered as a more important contributor to seed Fe concentration, even though the ratio may greatly vary among species (Hocking and Pate, 1977). In Arabidopsis, it was concluded that the xylem provides $60-70 \%$ of the total seed Fe content, whereas the remaining 30-40\% originates from senescing leaves, most likely via the phloem stream (Waters and Grusak, 2008). Differences between species are likely to exist, as discussed in (Stomph et al., 2009) for the case of xylem discontinuity at the base of cereal seeds. This discontinuity is absent in rice and therefore allows solutes in the xylem to flow through the seed without symplasmic unloading.

\section{STORAGE OF Fe IN Seeds}

Inside seeds, $\mathrm{Fe}$ is essential for embryo development (Stacey et al., 2002; Stacey et al., 2008) but might also become toxic at high concentration. Thus, Fe must be transported into embryos and stored in a stable form that can be remobilized during germination. Embryo Fe transport has rarely been addressed experimentally, although this process is highly relevant for both increasing the seed Fe content and to preserve the fitness of the embryo. Only few genes encoding proteins with functions in Fe transport within seeds have been identified. OsYSL2 encodes a
PM Fe-NA transporter and is expressed in various parts of the seed throughout its development (Koike et al., 2004). The role of OsYSL2 in the transport of Fe to the seed was further confirmed using a RNAi line (Ishimaru et al., 2010). Disruption of AtOPT3 leads to embryo lethality and decreased expression of the gene (as observed in the opt3-2 mutant) resulted in reduced Fe content of the embryo (Stacey et al., 2008). The substrate of AtOPT3 is unknown. The citrate efflux transporter FRD3 is expressed in the aleurone layer and in the embryo protodermis, and is known to promote Fe nutrition between symplastically disconnected tissues (Roschzttardtz et al., 2011b). For both AtOPT3 and AtFRD3 the precise function in embryo Fe uptake remains to be elucidated.

Development of elemental imaging techniques allowed accurate localization of Fe in seeds of Arabidopsis, rice, and pea (Kim et al., 2006; Roschzttardtz et al., 2009, 2011 a; Takahashi et al., 2009; Iwai et al., 2012). The results of these studies highlighted major differences between species. In rice seeds, the highest Fe concentration was observed in aleurone layers, integument, and in the scutellum (Figure 2A). These tissues are discarded during processing; hence in this species, breeding focused on increasing endosperm Fe content (Goto et al., 1999; Lee et al., 2009) in order to enhance Fe bioavailability (Bashir et al., 2010). In dicots, the endosperm represents a minor portion of mature seeds, and $\mathrm{Fe}$ is mainly stored within the embryo. Raising the Fe content in such seeds may therefore be associated with a possible damage of the embryo by toxic Fe concentrations. To prevent such damage, plants possess two mechanisms. Iron can be stored in plastids within ferritins, which assemble as large spherical 24 -mer protein complexes able to store up to $4500 \mathrm{Fe}$ atoms in their internal cavities. The second mechanism consists in vacuolar sequestration.

In Arabidopsis, during maturation of the embryo $\mathrm{Fe}$ is sequestered in vacuoles of the endodermal cell layer (Figure 2B) through the VACUOLAR IRON TRANSPORTER1 (AtVIT1; (Kim et al., 2006), and then remobilized during germination by the NATURAL RESISTANCE ASSOCIATED MACROPHAGE PROTEIN3 and 4 (AtNRAMP3 and AtNRAMP4; Lanquar et al., 2005; Roschzttardtz et al., 2009). Quantitatively, it has recently been shown that this particular Fe pool represents around $50 \%$ of the total Fe accumulated in Arabidopsis embryos (Schnell Ramos et al., 2013). The scenario is quite different in pea embryos where Fe concentration is highest in the epidermis and gradually decreases throughout the inner layers (Figure 2C). At the subcellular level, high Fe concentrations have been observed in nuclei and nucleoli although a quantitatively important fraction of Fe is stored in plastids, bound to ferritins (Lobréaux and Briat, 1991). This localization pattern is similar to that observed in leaves of other species (Roschzttardtz et al., 2011a) and young Arabidopsis embryos (Roschzttardtz et al., 2009). The diversity in Fe localization reflects different storage forms of Fe. Because of pronounced differences in bioavailability between different forms of $\mathrm{Fe}$, knowledge regarding the Fe ligands is critical for an effective biofortification strategy. Iron-phytate (inositol hexakisphosphate) is an example of non-available $\mathrm{Fe}$ (Hallberg et al., 1989). Phytic acids bind tightly to various cations that are not readily released during digestion by mammalians. Phytates are preferentially stored in vacuolar globoids (Wada and Lott, 1997) and constitute the main Fe storage pool of Arabidopsis embryos (Lanquar et al., 2005). Recent research has shown that 


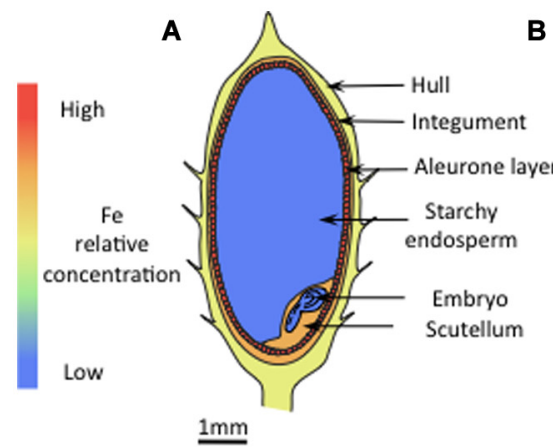

$\underline{1 \mathrm{~mm}}$
B

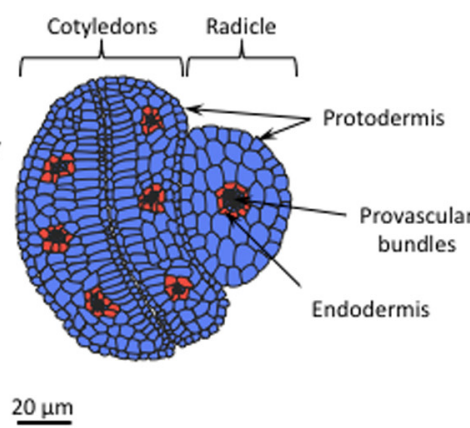

C

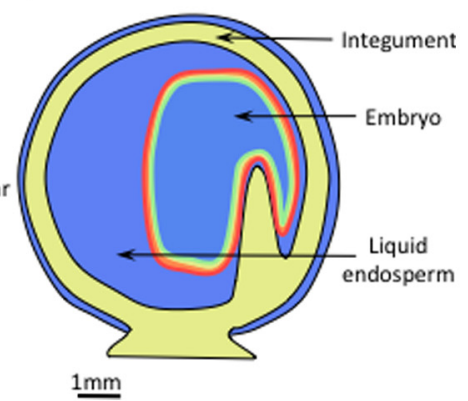

FIGURE 2 | Iron localization in seeds. (A) In rice, the concentration of $\mathrm{Fe}$ is highest in the aleurone layer, the integument, and the scutellum. Iron levels are also high in the hull. In the starchy endosperm the Fe content is low. (B) In Arabidopsis, Fe is mainly localized in vacuoles of endodermal cells that surround provascular tissues, whereas in other cells the Fe concentration is homogenously low. (C) In pea seeds, embryos constitute the main Fe storage pool, but unlike in Arabidopsis, $\mathrm{Fe}$ is localized in nuclei and plastids. The iron concentration is highest in the outer cell layers, progressively decreasing toward the inner layers. phytate represents also the main Fe storage in the rice aleurone layer (Persson et al., 2009; Iwai et al., 2012). In legume seeds, by contrast, highly bioavailable plastidic ferritin constitutes the main storage form of Fe (Lott et al., 1984; Lobréaux and Briat, 1991; Murray-Kolb et al., 2003; Davila-Hicks et al., 2004). Ferritin was successfully used to engineer rice lines with high seed Fe (Goto et al., 1999; Wirth et al., 2009), indicating that ferritin is a good candidate for biofortification purposes. Although not considered as a natural storage form of Fe, NA was also employed to breed Feenriched rice varieties, and manipulating NA content represents so far the most successful attempts regarding to both content and bioavailability of Fe. The first attempt (Masuda et al., 2009) consisted in the expression of the gene encoding barley NA synthase, $H v N A S 1$, in rice. Grains of lines overexpressing the NA synthase OsNAS3 contained around 3-fold more Fe than wild-type plants and were successfully used to heal anemic mice (Lee et al., 2009). Similar results were obtained by overexpressing OsNAS2 (Lee et al., 2012) and OsNAS1, specifically in the endosperm (Zheng et al., 2010). In fact, constitutive expression of OsNAS genes was shown to increase the Fe content of polished grains by 2.1- to 4.2-fold (Johnson et al., 2011). Multiple transgene approaches expressing both the ferritin gene from Phaseolus vulgaris (PvFERRITIN), the Arabidopsis NA synthase AtNAS1, and the phytase from Aspergillus fumigatus Afphytase were successful as well, with a report of a sixfold increase in rice seed Fe content (Wirth et al., 2009). Using a different combination of transgenes (HvNAS1, OsYSL2, and GmFERRITIN), Masuda et al. (2012) were able to produce fieldgrown plants with a 4.4-fold increase in Fe content in polished seeds without yield loss. The authors concluded that for efficient biofortification introduction of multiple Fe homeostasis genes is more effective than introduction of single genes.

\section{CONCLUSION}

In the last two decades, understanding of Fe homeostasis in plants has leapt forward dramatically; molecular biology progress led to the identification and functional characterization of many genes and regulatory nodes involved in Fe transport, evolution of analytical techniques has allowed accurate determination of labile Fe species, and, more recently, elemental imaging techniques such as X-ray fluorescence provided new insights into the distribution and trafficking of Fe. Data provided by this array of techniques set the stage for producing Fe-fortified plant varieties, illustrated by the recent achievements in rice (reviewed in Sperotto et al., 2012). Critical gaps in knowledge exist regarding the mechanisms controlling Fe homeostasis in green plant parts, loading and unloading of xylem and phloem, Fe transport within seeds, and, last but not least, regarding the shoot-to-root signal adjusting root Fe uptake to the shoot demand. These questions are pending for decades, complicated by the difficulty to sample phloem sap and intracellular fluids (Kehr and Rep, 2007). Further progress in deciphering the function of several unknown Fe-responsive genes in combination with further technical progress, providing a better resolution of Fe speciation and concentration, will lead to improved strategies to generate Fe-efficient germplasms and to combat FDA.

\section{NOTES}

Since this paper was completed and accepted for publication, the role of ascorbate in iron transport by pea and Arabidopsis embryos was unambiguously demonstrated by Grillet et al. (2013).

\section{ACKNOWLEDGMENTS}

Work in the Schmidt laboratory is supported by grants from Academia Sinica and the National Science Council.

\section{REFERENCES}

Bashir, K., Ishimaru, Y., and Nishizawa, N. (2010). Iron uptake and loading into rice grains. Rice 3, 122-130. doi: 10.1007/s12284-010-9042-y

Bashir, K., Ishimaru, Y., Shimo, H., Kakei, Y., Senoura, T., Takahashi, R., et al. (2011). Rice phenolics efflux transporter 2 (PEZ2) plays an important role in solubilizing apoplasmic iron. Soil Sci. Plant Nutr. 57, 803-812. doi: 10.1080/00380768.2011.637305

Bienfait, H., and Scheffers, M. (1992). Some properties of ferric citrate relevant to the iron nutrition of plants. Plant Soil 143, 141-144. doi: 10.1007/BF00009139

Blair, M. W., Knewtson, S. J. B., Astudillo, C., Li, C. M., Fernandez, A. C., and Grusak, M. A. (2010). Variation and inheritance of iron reductase activity in the roots of common bean (Phaseolus vulgaris L.) and association with seed iron accumulation QTL. BMC Plant Biol. 10:215. doi: 10.1186/1471-2229-10-215 
Brown, J. C., and Chaney, R. L. (1971). Effect of iron on transport of citrate into xylem of soybeans and tomatoes. Plant Physiol. 47, 836-840. doi: 10.1104/pp.47.6.836

Conklin, P. L., Saracco, S. A., Norris, S. R., and Last, R. L. (2000). Identification of ascorbic acid-deficient Arabidopsis thaliana mutants. Genetics 154, 847-856.

Curie, C., Cassin, G., Couch, D., Divol, F., Higuchi, K., Jean, M., et al. (2009). Metal movement within the plant: contribution of nicotianamine and YELLOW STRIPE 1-LIKE transporters. Ann. Bot. 103, 1-11. doi: 10.1093/aob/mcn207

Curie, C., Panaviene, Z., Loulergue, C., Dellaporta, S. L., Briat, J. F., and Walker, E. L. (2001). Maize YELLOW STRIPE1 encodes a membrane protein directly involved in Fe(III) uptake. Nature 409, 346-349. doi: 10.1038/35053080

Davila-Hicks, P., Theil, E. C., and Lönnerdal, B. (2004). Iron in ferritin or in salts (ferrous sulfate) is equally bioavailable in nonanemic women. Am. J. Clin. Nutr. 80, 936-940.

Durrett, T. P., Gassmann, W., and Rogers, E. E. (2007). The FRD3-mediated efflux of citrate into the root vasculature is necessary for efficient iron translocation. Plant Physiol. 144, 197-205. doi: 10.1104/pp.107.097162

Eide, D., Broderius, M., Fett, J., and Guerinot, M. L. (1996). A novel iron-regulated metal transporter from plants identified by functional expression in yeast. Proc. Natl. Acad. Sci. U.S.A. 93, 5624-5628. doi: 10.1073/pnas.93.11.5624

Fernandez-Calvino, L., Faulkner, C., Walshaw, J., Saalbach, G., Bayer, E., BenitezAlfonso, Y., etal. (2011). Arabidopsis plasmodesmal proteome. PLoS ONE 6:e18880. doi: 10.1371/journal.pone.0018880

Fourcroy, P., Siso-Terraza, P., Sudre, D., Saviron, M., Reyt, G., Gaymard, F., et al. (2013). Involvement of the ABCG37 transporter in secretion of scopoletin and derivatives by Arabidopsis roots in response to iron deficiency. New Phytol. 201, 155-167. doi: 10.1111/nph.12471

Foyer, C. H., and Lelandais, M. (1996). A comparison of the relative rates of transport of ascorbate and glucose across the thylakoid, chloroplast and plasmalemma membranes of pea leaf mesophyll cells. J. Plant Physiol. 148, 391-398. doi: 10.1016/S0176-1617(96)80271-9

García, M., Romera, F., Stacey, M., Stacey, G., Villar, E., Alcántara, E., et al. (2013). Shoot to root communication is necessary to control the expression of ironacquisition genes in Strategy I plants. Planta 237, 65-75. doi: 10.1007/s00425012-1757-0

Gendre, D., Czernic, P., Conejero, G., Pianelli, K., Briat, J. F., Lebrun, M., et al. (2007). TcYSL3, a member of the YSL gene family from the hyper-accumulator Thlaspi caerulescens, encodes a nicotianamine-Ni/Fe transporter. Plant J. 49, 1-15. doi: 10.1111/j.1365-313X.2006.02937.x

Goto, F., Yoshihara, T., Shigemoto, N., Toki, S., and Takaiwa, F. (1999). Iron fortification of rice seed by the soybean ferritin gene. Nature Biotechnol. 17, 282-286. doi: 10.1038/7029

Grillet, L., Ouerdane, L., Hoang, M. T. T., Isaure, M. P., Lobinski, R., Curie, C., et al. (2013). Ascorbate efflux as a new strategy for iron reduction and transport in plants. J. Biol. Chem. doi: 10.1074/jbc.M113.514828

Grinstead, R. R. (1960). The oxidation of ascorbic acid by hydrogen peroxide Catalysis by ethylenediaminetetraacetato-iron(III). J. Am. Chem. Soc. 82, 34643471. doi: 10.1021/ja01498a057

Grusak, M. A., and Pezeshgi, S. (1996). Shoot-to-root signal transmission regulates root Fe(III) reductase activity in the dgl mutant of pea. Plant Physiol. 110, 329-334.

Hallberg, L., Brune, M., and Rossander, L. (1989). Iron absorption in man: ascorbic acid and dose-dependent inhibition by phytate. Am. J. Clin. Nutr. 49, 140-144.

Hindt, M. N., and Guerinot, M. L. (2012). Getting a sense for signals: regulation of the plant iron deficiency response. Biochim. Biophys. Acta 1823, 1521-1530. doi: 10.1016/j.bbamcr.2012.03.010

Hocking, P. J., and Pate, J. S. (1977). Mobilization of minerals to developing seeds of legumes. Ann. Bot. 41, 1259-1278.

Inoue, H., Kobayashi, T., Nozoye, T., Takahashi, M., Kakei, Y., Suzuki, K., et al. (2009). Rice OsYSL15 is an iron-regulated iron(III)-deoxymugineic acid transporter expressed in the roots and is essential for iron uptake in early growth of the seedlings. J. Biol. Chem. 284, 3470-3479. doi: 10.1074/jbc.M806042200

Ishimaru, Y., Kakei, Y., Shimo, H., Bashir, K., Sato, Y., Sato, Y., et al. (2011). A rice phenolic efflux transporter is essential for solubilizing precipitated apoplasmic iron in the plant stele. J. Biol. Chem. 286, 24649-24655. doi: 10.1074/jbc.M111. 221168

Ishimaru, Y., Masuda, H., Bashir, K., Inoue, H., Tsukamoto, T., Takahashi, M., et al. (2010). Rice metal-nicotianamine transporter, OsYSL2, is required for the long-distance transport of iron and manganese. Plant J. 62, 379-390. doi: 10.1111/j.1365-313X.2010.04158.x

Ishimaru, Y., Suzuki, M., Tsukamoto, T., Suzuki, K., Nakazono, M., Kobayashi, T., et al. (2006). Rice plants take up iron as an Fe3+-phytosiderophore and as $\mathrm{Fe} 2+$. Plant J. 45, 335-346. doi: 10.1111/j.1365-313X.2005.02624.X

Iwai, T., Takahashi, M., Oda, K., Terada, Y., and Yoshida, K. T. (2012). Dynamic changes in the distribution of minerals in relation to phytic acid accumulation during rice seed development. Plant Physiol. 160, 2007-2014. doi: 10.1104/pp.112.206573

Jeong, J., Cohu, C., Kerkeb, L., Pilon, M., Connolly, E. L., and Guerinot, M. L. (2008). Chloroplast $\mathrm{Fe}$ (III) chelate reductase activity is essential for seedling viability under iron limiting conditions. Proc. Natl. Acad. Sci. U.S.A. 105, 10619-10624. doi: 10.1073/pnas.0708367105

Jeong, J., and Connolly, E. L. (2009). Iron uptake mechanisms in plants: functions of the FRO family of ferric reductases. Plant Sci. 176, 709-714. doi 10.1016/j.plantsci.2009.02.011

Johnson, A. a. T., Kyriacou, B., Callahan, D. L., Carruthers, L., Stangoulis, J., Lombi, E., et al. (2011). Constitutive overexpression of the OsNAS gene family reveals single-gene strategies for effective iron- and zinc-biofortification of rice endosperm. PLOS ONE 6:e24476. doi:10.1371/journal.pone.0024476

Kehr, J., and Rep, M. (2007). Protein extraction from xylem and phloem sap. Methods Mol. Biol. 355, 27-35.

Kim, S. A., Punshon, T., Lanzirotti, A., Li, L. T., Alonso, J. M., Ecker, J. R., et al. (2006). Localization of iron in Arabidopsis seed requires the vacuolar membrane transporter VIT1. Science 314, 1295-1298. doi: 10.1126/science.1132563

Klatte, M., Schuler, M., Wirtz, M., Fink-Straube, C., Hell, R., and Bauer, P. (2009). The analysis of Arabidopsis nicotianamine synthase mutants reveals functions for nicotianamine in seed iron loading and iron deficiency responses. Plant Physiol. 150, 257-271. doi: 10.1104/pp.109.136374

Koike, S., Inoue, H., Mizuno, D., Takahashi, M., Nakanishi, H., Mori, S., et al. (2004). OsYSL2 is a rice metal-nicotianamine transporter that is regulated by iron and expressed in the phloem. Plant J. 39, 415-424. doi: 10.1111/j.1365313X.2004.02146.x

Krüger, C., Berkowitz, O., Stephan, U. W., and Hell, R. (2002). A metal-binding member of the late embryogenesis abundant protein family transports iron in the phloem of Ricinus communis L. J. Biol. Chem. 277, 25062-25069. doi: 10.1074/jbc.M201896200

Lalonde, S., Tegeder, M., Throne-Holst, M., Frommer, W. B., and Patrick, J. W. (2003). Phloem loading and unloading of sugars and amino acids. Plant Cell Environ. 26, 37-56. doi: 10.1046/j.1365-3040.2003.00847.x

Lane, D. J. R., and Lawen, A. (2008). Non-transferrin iron reduction and uptake are regulated by transmembrane ascorbate cycling in K562 cells. J. Biol. Chem. 283, 12701-12708. doi: 10.1074/jbc.M800713200

Lanquar, V., Lelievre, F., Bolte, S., Hames, C., Alcon, C., Neumann, D., et al. (2005). Mobilization of vacuolar iron by AtNRAMP3 and AtNRAMP4 is essential for seed germination on low iron. EMBO J. 24, 4041-4051. doi: 10.1038/sj.emboj. 7600864

Le Jean, M., Schikora, A., Mari, S., Briat, J. F., and Curie, C. (2005). A loss-of-function mutation in AtYSL1 reveals its role in iron and nicotianamine seed loading. Plant J. 44, 769-782. doi: 10.1111/j.1365-313X.2005.02569.X

Lee, S., Jeon, U. S., Lee, S. J., Kim, Y. K., Persson, D. P., Husted, S., et al. (2009). Iron fortification of rice seeds through activation of the nicotianamine synthase gene. Proc. Natl. Acad. Sci. U.S.A. 106, 22014-22019. doi: 10.1073/pnas.09109 50106

Lee, S., Kim, Y. -S., Jeon, U., Kim, Y.-K., Schjoerring, J., and An, G. (2012). Activation of rice nicotianamine synthase 2 (OsNAS2) enhances iron availability for biofortification. Mol. Cells 33, 269-275. doi: 10.1007/s10059-012-2231-3

Lin, Y. F., Liang, H. M., Yang, S. Y., Boch, A., Clemens, S., Chen, C. C., et al. (2009). Arabidopsis IRT3 is a zinc-regulated and plasma membrane localized zinc/iron transporter. New Phytol. 182, 392-404. doi: 10.1111/j.1469-8137.2009. 02766.x

Ling, H. Q., Koch, G., Baumlein, H., and Ganal, M. W. (1999). Map-based cloning of chloronerva, a gene involved in iron uptake of higher plants encoding nicotianamine synthase. Proc. Natl. Acad. Sci. U.S.A. 96, 7098-7103. doi: 10.1073/pnas.96.12.7098

Lobréaux, S., and Briat, J. F. (1991). Ferritin accumulation and degradation in different organs of pea (Pisum sativum) during development. Biochem. J. 274, 601-606. 
Lott, J., Goodchild, D., and Craig, S. (1984). Studies of mineral reserves in pea (Pisum sativum) cotyledons using low-water-content procedures. Funct. Plant Biol. 11, 459-469.

Lubkowitz, M. A., Hauser, L., Breslav, M., Naider, F., and Becker, J. M. (1997). An oligopeptide transport gene from Candida albicans. Microbiology 143, 387-396. doi: 10.1099/00221287-143-2-387

Lubkowitz, M. A., Barnes, D., Breslav, M., Burchfield, A., Naider, F., and Becker, J. M. (1998). Schizosaccharomyces pombe isp4 encodes a transporter representing a novel family of oligopeptide transporters. Mol. Microbiol. 28, 729-741. doi: 10.1046/j.1365-2958.1998.00827.x

Masuda, H., Usuda, K., Kobayashi, T., Ishimaru, Y., Kakei, Y., Takahashi, M., et al. (2009). Overexpression of the barley nicotianamine synthase gene HvNAS1 increases iron and zinc concentrations in rice grains. Rice 2, 155-166. doi: 10.1007/s12284-009-9031-1

Masuda, H., Ishimaru, Y., Sann Aung, M., Kobayashi, T., Kakei, Y., Takahashi, M., et al. (2012). Iron biofortification in rice by the introduction of multiple genes involved in iron nutrition. Sci. Rep. 2:543. doi: 10.1038/srep 00543

Morrissey, J., Baxter, I. R., Lee, J., Li, L. T., Lahner, B., Grotz, N., et al. (2009). The ferroportin metal efflux proteins function in iron and cobalt homeostasis in Arabidopsis. Plant Cell 21, 3326-3338. doi: 10.1105/tpc.109. 069401

Mukherjee, I., Campbell, N. H., Ash, J. S., and Connolly, E. L. (2006). Expression profiling of the Arabidopsis ferric chelate reductase (FRO) gene family reveals differential regulation by iron and copper. Planta 223, 1178-1190. doi: 10.1007/s00425-005-0165-0

Murray-Kolb, L. E., Welch, R., Theil, E. C., and Beard, J. L. (2003). Women with low iron stores absorb iron from soybeans. Am. J. Clin. Nutr. 77, 180-184.

Nishiyama, R., Kato, M., Nagata, S., Yanagisawa, S., and Yoneyama, T. (2011). Identification of Zn-nicotianamine and Fe-2'-deoxymugineic acid in the phloem sap from rice plants (Oryza sativa L.). Plant Cell Physiol. 53, 381-390. doi: $10.1093 / \mathrm{pcp} / \mathrm{pcr} 188$

Noma, M., Noguchi, M., and Tamaki, E. (1971). New amino acid, nicotianamine, from tobacco leaves. Tetrahedron Lett. 12, 2017-2020. doi: 10.1016/S00404039(01)96769-3

Nozoye, T., Nagasaka, S., Kobayashi, T., Takahashi, M., Sato, Y., Uozumi, N., etal. (2011). Phytosiderophore efflux transporters are crucial for iron acquisition in graminaceous plants. J. Biol. Chem. 286, 5446-5454. doi: 10.1074/jbc.M110.180026

Palmer, C. M., and Guerinot, M. L. (2009). Facing the challenges of $\mathrm{Cu}, \mathrm{Fe}$ and $\mathrm{Zn}$ homeostasis in plants. Nat. Chem. Biol. 5, 333-340. doi: 10.1038/nchembio.166

Patrick, J. W., and Offler, C. E. (2001). Compartmentation of transport and transfer events in developing seeds. J. Exp. Bot. 52, 551-564. doi: 10.1093/jexbot/52.356.551

Persson, D. P., Hansen, T. H., Laursen, K. H., Schjoerring, J. K., and Husted, S. (2009). Simultaneous iron, zinc, sulfur and phosphorus speciation analysis of barley grain tissues using SEC-ICP-MS and IP-ICP-MS. Metallomics 1, 418-426. doi: 10.1039/b905688b

Procházka, Ž., and Scholz, G. (1984). Nicotianamine, the 'normalizing factor' for the auxotroph tomato mutant Chloronerva; a representative of a new class of plant effectors. Experientia 40, 794-801. doi: 10.1007/BF01951961

Rautenkranz, A. A. F., Li, L. J., Machler, F., Martinoia, E., and Oertli, J. J. (1994). Transport of ascorbic and dehydroascorbic acids across protoplast and vacuole membranes isolated from barley (Hordeum vulgare cv Gerbel) leaves. Plant Physiol. 106, 187-193.

Rellan-Alvarez, R., Abadia, J., and Alvarez-Fernandez, A. (2008). Formation of metal-nicotianamine complexes as affected by $\mathrm{pH}$, ligand exchange with citrate and metal exchange. a study by electrospray ionization time-of-flight mass spectrometry. Rapid Commun. Mass Spectrom 22, 1553-1562. doi: $10.1002 / \mathrm{rcm} .3523$

Rellan-Alvarez, R., Giner-Martinez-Sierra, J., Orduna, J., Orera, I., RodriguezCastrillon, J. A., Garcia-Alonso, J. I., et al. (2010). Identification of a tri-iron(III), tri-citrate complex in the xylem sap of iron-deficient tomato resupplied with iron: new insights into plant iron long-distance transport. Plant Cell Physiol. 51, 91-102. doi: 10.1093/pcp/pcp170

Robinson, N. J., Procter, C. M., Connolly, E. L., and Guerinot, M. L. (1999). A ferric-chelate reductase for iron uptake from soils. Nature 397, 694-697. doi: $10.1038 / 17800$
Rodriguez-Celma, J., Lin, W. D., Fu, G. M., Abadia, J., Lopez-Millan, A. F., and Schmidt, W. (2013). Mutually exclusive alterations in secondary metabolism are critical for the uptake of insoluble iron compounds by Arabidopsis and Medicago truncatula. Plant Physiol. 162, 1473-1485. doi: 10.1104/pp.113. 220426

Rogers, E. E., Wu, X., Stacey, G., and Nguyen, H. T. (2009). Two MATE proteins play a role in iron efficiency in soybean. J. Plant Physiol. 166, 1453-1459. doi: 10.1016/j.jplph.2009.02.009

Römheld, V., and Marschner, H. (1983). Mechanism of iron uptake by peanut plants - I. Fe(III) reduction, chelate splitting, and release of phenolics. Plant Physiol. 71, 949-954.

Roschzttardtz, H., Conéjéro, G., Curie, C., and Mari, S. (2009). Identification of the endodermal vacuole as the iron storage compartment in the Arabidopsis embryo. Plant Physiol. 151, 1-10. doi: 10.1104/pp.109.144444

Roschzttardtz, H., Conèjèro, G., Divol, F., Alcon, C., Verdeil, J. -L., Curie, C., et al. (2013). New insights into Fe localization in plant tissues. Front. Plant Sci. 4, 350. doi: 10.3389/fpls.2013.00350

Roschzttardtz, H., Grillet, L., Isaure, M. P., Conejero, G., Ortega, R., Curie, C., et al. (2011a). Plant cell nucleolus as a hot spot for iron. J. Biol. Chem. 286, 27863-27866. doi: 10.1074/jbc.C111.269720

Roschzttardtz, H., Séguéla-Arnaud, M., Briat, J. -F., Vert, G., and Curie, C. (2011b). The FRD3 citrate effluxer promotes iron nutrition between symplastically disconnected tissues throughout Arabidopsis development. Plant Cell 23, 2725-2737. doi: $10.1105 /$ tpc. 111.088088

Santi, S., and Schmidt, W. (2009). Dissecting iron deficiency-induced proton extrusion in Arabidopsis roots. New Phytol. 183, 1072-1084. doi: 10.1111/j.14698137.2009.02908.x

Sayers, M. H., Lynch, S. R., Jacobs, P., Charlton, R. W., Bothwell, T. H., Walker, R. B., et al. (1973). The Effects of ascorbic acid supplementation on the absorption of iron in maize, wheat and soya. Br. J. Haematol. 24, 209-218. doi: 10.1111/j.13652141.1973.tb05741.x

Schaaf, G., Ludewig, U., Erenoglu, B. E., Mori, S., Kitahara, T., and Von Wiren, N. (2004). ZmYS1 functions as a proton-coupled symporter for phytosiderophoreand nicotianamine-chelated metals. J. Biol. Chem. 279, 9091-9096. doi: 10.1074/jbc.M311799200

Schnell Ramos, M., Khodja, H., Mary, V., and Thomine, S. (2013). Using $\mu$ PIXE for quantitative mapping of metal concentration in Arabidopsis thaliana seeds. Front. Plant Sci. 4:168. doi: 10.3389/fpls.2013.00168

Schuler, M., Rellàn-Alvarez, R., Fink-Straube, C., Abadia, J., and Bauer, P. (2012). Nicotianamine functions in the phloem-based transport of iron to sink organs, in pollen development and pollen tube growth in Arabidopsis. Plant Cell 24, 2380-2400. doi: 10.1105/tpc.112.099077

Shanmugam, V., Lo, J. C., Wu, C. L., Wang, S. L., Lai, C. C., Connolly, E. L., et al. (2011). Differential expression and regulation of iron-regulated metal transporters in Arabidopsis halleri and Arabidopsis thaliana - The role in zinc tolerance. New Phytol. 190, 125-137. doi: 10.1111/j.1469-8137.2010.03606.x

Sperotto, R. A., Ricachenevsky, F. K., Waldow, V. D. A., and Fett, J. P. (2012). Iron biofortification in rice: it's a long way to the top. Plant Sci. 190, 24-39. doi: 10.1016/j.plantsci.2012.03.004

Stacey, M. G., Koh, S., Becker, J., and Stacey, G. (2002). AtOPT3, a member of the oligopeptide transporter family, is essential for embryo development in Arabidopsis. Plant Cell 14, 2799-2811. doi: 10.1105/tpc.005629

Stacey, M. G., Patel, A., Mcclain, W. E., Mathieu, M., Remley, M., Rogers, E. E., et al. (2008). The Arabidopsis AtOPT3 protein functions in metal homeostasis and movement of iron to developing seeds. Plant Physiol. 146, 589-601. doi: 10.1104/pp.107.108183

Stadler, R., Lauterbach, C., and Sauer, N. (2005). Cell-to-cell movement of green fluorescent protein reveals post-phloem transport in the outer integument and identifies symplastic domains in Arabidopsis seeds and embryos. Plant Physiol. 139, 701-712. doi: 10.1104/pp.105.065607

Stoltzfus, R. J. (2003). Iron deficiency: global prevalence and consequences. Food Nutr. Bull. 24, 99-103.

Stomph, J. T., Jiang, W., and Struik, P. C. (2009). Zinc biofortification of cereals: rice differs from wheat and barley. Trends Plant Sci. 14, 123-124. doi: 10.1016/j.tplants.2009.01.001

Takahashi, M., Nozoye, T., Kitajima, N., Fukuda, N., Hokura, A., Terada, Y., et al. (2009). In vivo analysis of metal distribution and expression of metal transporters in rice seed during germination process by microarray and X-ray fluorescence 
imaging of Fe, Zn, Mn, and Cu. Plant Soil 325, 39-51. doi: 10.1007/s11104-0090045-7

Thomine, S., and Vert, G. (2013). Iron transport in plants: better be safe than sorry. Curr. Opin. Plant Biol. 16, 322-327. doi: 10.1016/j.pbi.2013.01.003

Urzica, E. I., Casero, D., Yamasaki, H., Hsieh, S. I., Adler, L. N., Karpowicz, S. J., et al. (2012). Systems and trans-system level analysis identifies conserved iron deficiency responses in the plant lineage. Plant Cell 24, 3921-3948. doi: 10.1105/tpc.112.102491

Van Dongen, J. T., Ammerlaan, A. M. H., Wouterlood, M., Van Aelst, A. C., and Borstlap, A. C. (2003). Structure of the developing pea seed coat and the post-phloem transport pathway of nutrients. Ann. Bot. 91, 729-737. doi: 10.1093/aob/mcg066

Vert, G., Grotz, N., Dedaldechamp, F., Gaymard, F., Guerinot, M. L., Briat, J. F., et al. (2002). IRT1, an Arabidopsis transporter essential for iron uptake from the soil and for plant growth. Plant Cell 14, 1223-1233. doi: 10.1105/tpc.001388

von Wiren, N., Klair, S., Bansal, S., Briat, J. F., Khodr, H., Shioiri, T., et al. (1999). Nicotianamine chelates both Fe-III and Fe-II. Implications for metal transport in plants. Plant Physiol. 119, 1107-1114. doi: 10.1104/pp.119.3.1107

Wada, T., and Lott, J. N. A. (1997). Light and electron microscopic and energy dispersive X-ray microanalysis studies of globoids in protein bodies of embryo tissues and the aleurone layer of rice (Oryza sativa L.) grains. Can. J. Bot. 75, 1137-1147. doi: 10.1139/b97-125

Waters, B. M., Chu, H. H., Didonato, R. J., Roberts, L. A., Eisley, R. B., Lahner, B., et al. (2006). Mutations in Arabidopsis YELLOW STRIPE-LIKE1 and YELLOW STRIPE-LIKE3 reveal their roles in metal ion homeostasis and loading of metal ions in seeds. Plant Physiol. 141, 1446-1458. doi: 10.1104/pp.106.082586

Waters, B. M., and Grusak, M. A. (2008). Whole-plant mineral partitioning throughout the life cycle in Arabidopsis thaliana ecotypes Columbia, Landsberg erecta, Cape Verde Islands, and the mutant line ysllysl3. New Phytol. 177, 389-405.

Wintz, H., Fox, T., Wu, Y. Y., Feng, V., Chen, W. Q., Chang, H. S., et al. (2003). Expression profiles of Arabidopsis thaliana in mineral deficiencies reveal novel transporters involved in metal homeostasis. J. Biol. Chem. 278, 47644-47653. doi: 10.1074/jbc.M309338200

Wirth, J., Poletti, S., Aeschlimann, B., Yakandawala, N., Drosse, B., Osorio, S. et al. (2009). Rice endosperm iron biofortification by targeted and synergistic action of nicotianamine synthase and ferritin. Plant Biotechnol. J. 7, 631-644. doi: 10.1111/j.1467-7652.2009.00430.x

Wu, H. L., Li, L. H., Du, J., Yuan, Y. X., Cheng, X. D., and Ling, H. Q. (2005). Molecular and biochemical characterization of the $\mathrm{Fe}$ (III) chelate reductase gene family in Arabidopsis thaliana. Plant Cell Physiol. 46, 1505-1514. doi: 10.1093/pcp/ pcil63

Yokosho, K., Yamaji, N., Ueno, D., Mitani, N., and Ma, J. F. (2009). OsFRDL1 is a citrate transporter required for efficient translocation of iron in rice. Plant Physiol. 149, 297-305. doi: 10.1104/pp.108.128132

Zaharieva, T. B., and Abadía, J. (2003). Iron deficiency enhances the levels of ascorbate, glutathione, and related enzymes in sugar beet roots. Protoplasma 221, 269-275.

Zheng, L. Q., Cheng, Z. Q., Ai, C. X., Jiang, X. H., Bei, X. S., Zheng, Y., et al. (2010). Nicotianamine, a novel enhancer of rice iron bioavailability to humans. PLoS ONE 5:e10190. doi:10.1371/journal.pone.0010190

Zimmermann, M. B., and Hurrell, R. F. (2007). Nutritional iron deficiency. Lancet 370, 511-520. doi: 10.1016/S0140-6736(07)61235-5

Conflict of Interest Statement: The authors declare that the research was conducted in the absence of any commercial or financial relationships that could be construed as a potential conflict of interest.

Received: 15 October 2013; paper pending published: 01 November 2013; accepted: 11 December 2013; published online: 02 January 2014.

Citation: Grillet L, Mari S and Schmidt W (2014) Iron in seeds - loading pathways and subcellular localization. Front. Plant Sci. 4:535. doi: 10.3389/fpls.2013.00535

This article was submitted to Plant Nutrition, a section of the journal Frontiers in Plant Science.

Copyright (C) 2014 Grillet, Mari and Schmidt. This is an open-access article distributed under the terms of the Creative Commons Attribution License (CC BY). The use, distribution or reproduction in other forums is permitted, provided the original author(s) or licensor are credited and that the original publication in this journal is cited, in accordance with accepted academic practice. No use, distribution or reproduction is permitted which does not comply with these terms. 